\title{
SEXUALIDADE E MÍDIA: DISCURSOS JORNALÍSTICOS SOBRE O "SEXUAL" E VIDA PRIVADA"
}

Ivia Maksud

\begin{abstract}
RESUMO. O artigo discute significados sobre sexualidade no discurso jornalístico. São investigados dois jornais cariocas, pertencentes à mesma organização empresarial e destinados a públicos leitores diferenciados. A análise prioriza espaços destinados à exposição da vida íntima dos leitores e o debate de certos aspectos da vida privada. Ao longo do trabalho, demonstra-se que os jornais funcionam como uma forma idealizada de expressar a cultura de segmentos sociais a que se destinam. Valores em torno do sexo e da sexualidade produzidos pela indústria cultural dirigida a esses segmentos estão referendados pelo idioma classificatório de gênero, resultando ora em abordagens mais "tradicionais" - expressando uma concepção de mundo dicotomizada no tocante ao gênero e à sexualidade - ora em perspectivas mais "modernas" - que concebem as relações entre os sexos de forma mais igualitária. Conclui-se que a mídia é uma agência importante e ágil no processo de construção de fatos sociais, entre os quais a sexualidade.
\end{abstract}

Palavras-chave: mídia, sexualidade, práticas sexuais.

\section{SEXUALITY AND MEDIA: JOURNALISTIC DISCOURSES ON "SEX" AND PRIVATE LIFE}

\begin{abstract}
Tourism creates social, cultural and health impacts on host communities. Current paper analyzes, through an ethnographic Current article discusses sexual meanings in journalistic discourse. Two Brazilian newspapers, hailing from the same publisher, albeit aimed at different readers, were analyzed. The analysis focuses on spaces reserved for the exhibition of the intimate life of readers and the debate on certain aspects of their private life. Investigation showed that the newspapers have an idealized form of expressing the culture of social segments, each according to their readers. Values on sexuality produced by the cultural industry for such readers use genderdistinctive language. They may thus have both traditional and modern approaches. In the former, gender and sexuality are dichotomized; in the latter, the relationships among the sexes are more egalitarian. Results show that the social media is an important and agile agency in the process of construction of social facts such as sexuality.
\end{abstract}

Key words: Social media, sexuality, sexual practices.

\section{LA SEXUALIDAD Y MEDIOS DE COMUNICACIÓN: LOS DISCURSOS PERIODÍSTICOS SOBRE LO 'SEXUAL' Y LA VIDA PRIVADA}

RESUMEN. El artículo discute significados sobre sexualidad en el discurso periodístico. Son investigados dos periódicos (prensas) cariocas que pertenecen a la misma organización empresarial pero destinados a públicos diferentes. El análisis prioriza espacios destinados a la exposición de la vida íntima de los lectores y el debate de determinados aspectos de la vida privada. A lo largo del trabajo se demuestra que los periódicos funcionan como una forma idealizada de expresarla cultura de los segmentos sociales a los cuales están destinados. Valores alrededor del sexo y de la sexualidad producidos por la industria cultural dirigida e esos segmentos están refrendados por le idioma clasificatorio de género, resultando por momentos en abordajes más "tradicionales" -expresando una concepción del mundo dicotómica entre género y sexualidad- y en otros en perspectivas más "modernas" -que conciben las relaciones entre los sexos deforma igualitaria. Se concluye que los medios de comunicación son una agencia importante y ágil en el proceso de construcción de los hechos sociales, entre los que está la sexualidad.

Palabras-clave: Medios de comunicación, sexualidad, practicas sexuales.

1 Este texto é uma versão reformulada do debate empreendido originalmente na minha dissertação de mestrado, sobre sexualidade e mídia impressa (Maksud, 2000). Ele se baseia em dados de investigação que se referem à realidade apresentada pelos jornais à época de realização da pesquisa.

* Doutora em Saúde Coletiva; Coordenadora de Projetos da Associação Brasileira Interdisciplinar de AIDS-ABIA e Professora do Instituto Brasileiro de Medicina de Reabilitação-IBMR.

Autores convidados. 
Por ser uma instância socializadora capaz de atingir amplos contingentes de pessoas, colocar em evidência valores e legitimar práticas sociais, a mídia tem se colocado como forte objeto de investigação em várias áreas. Os estudos têm demonstrado seu potencial de construção de significados e alteração da realidade, seja na criação de mecanismos capazes de legitimar políticas ou interesses (Brigeiro \& Maksud, no prelo; Luz, 1979) ou significar uma doença como aids (Galvão, 1992; Herzlich \& Pierret, 1992), seja em fazer existirem fatos sociais diversos (Burke, 1996). Com alto grau de alcance em curto espaço de tempo, os meios de comunicação produzem significados através das informações que veiculam e de seu lócus, privilegiado pela lógica de mercado (Bourdieu, 1996).

A mídia impressa é uma fatia de destaque dos meios de comunicação, pelo seu papel de análise mediata ante a veiculação imediata de novos fatos pela TV, rádio e Internet (Bourdieu, 1996; LatmanWeltman, 1992) e por sua durabilidade e resistência, comprovadas à medida que o jornal pode ser lido, dobrado e transportado para qualquer lugar. A leitura do jornal é importante agência socializadora no dia-adia das pessoas.

A despeito das particularidades próprias de cada jornalista, entendemos o jornal como algo conformado por uma estrutura institucional e discursiva que tem regras preestabelecidas. No entanto, em se tratando de alguns jornais de grande circulação, a posição desses profissionais pode ganhar traços de distanciamento em relação à política editorial, resultando que, em alguns casos, a produção da notícia também esteja sujeita a influências advindas dos próprios jornalistas e de sua visão de mundo (Bourdieu, 1996).

Este artigo analisa o discurso sobre sexualidade difundido por dois jornais da mídia impressa carioca. Reconhecendo que há vários mecanismos na elaboração de notícias e que a produção discursiva sobre este tema não escapa a um complexo processo de construção social, o texto visa demonstrar a existência de normas e valores associados à idéia de sexualidade veiculada pelos jornais analisados. $\mathrm{O}$ ensaio discute dados obtidos em uma pesquisa que focalizou os jornais $O$ Globo e Extra no período de abril de 1998 a abril de 1999. O estudo procurou observar a recorrência de reportagens específicas sobre sexo, sexualidade e temas associados. A investigação contemplou todos os espaços do veículo, exceto os pagos, como anúncios, cadernos de classificados, de viagem, de informática e automóveis (Maksud, 2000).

No presente artigo observa-se o tratamento da sexualidade em cadernos dedicados à vida privada dos leitores no exercício de responder a algumas perguntas: Em que consistia o imaginário social sobre sexualidade nos dois jornais? Poder-se-ia delinear um quadro de regras de comportamento moral e sexual para cada jornal? Haveria diferenças na concepção de sexo e sexualidade na produção de noticias de acordo com o público leitor esperado?

\section{MÉTODO}

O discurso jornalístico é tomado como material etnográfico, a exemplo de DaMatta (1993) em relação a textos de literatura. Desta forma, os princípios estruturais dos textos e suas lógicas internas são valorizados em detrimento dos aspectos semióticos, que, obviamente, fazem parte de todo material jornalístico.

As matérias foram indexadas num banco de dados criado no software Access. Ao todo, foram classificados 2815 registros, sendo 1943 referentes ao O Globo e 813 referentes ao Extra. Uma entrevista semi-estruturada foi realizada com o editor-executivo de Extra para conhecer os objetivos do veículo, lançado em abril de $1998 .^{2}$

\section{Os dois jornais abordados no estudo}

$O$ Globo e Extra são jornais que pertencem à mesma organização empresarial, estão instalados em um mesmo espaço físico, mas contam com redação e jornalistas próprios. À época da pesquisa, compartilhavam um mesmo sistema informatizado de informações e parque gráfico. $O$ Globo é composto por aproximadamente sessenta páginas de segunda a sábado, com tiragem de trezentos mil exemplares. Aos domingos, contém cento e setenta páginas e tiragem de seiscentos mil exemplares. O jornal está à disposição tanto nas bancas de jornal como através de assinatura. Seu público leitor se constitui majoritariamente por mulheres que têm entre 50 e 65 anos, pertencem às classes alta e média e possuem nível de formação superior (Spink et al., 1997). Extra é composto por aproximadamente cinqüenta páginas, é editado de segunda a sábado e tem uma tiragem em torno de trezentos mil exemplares. Aos domingos, contém cento e trinta páginas e tiragem de quinhentos e quarenta mil exemplares. Não dispõe de serviço de assinatura, devido à incompatibilidade entre o custo

\footnotetext{
Até a época da conclusão da pesquisa (2000), o jornal Extra, criado em 1998, ainda não havia sido estudado sociologicamente. O jornal $O$ Globo foi objeto de pesquisa em ocasiões anteriores (por exemplo: Moraes, 1998; Spink et al., 1997; Boletim Olhar sobre a Mídia, 1997).
} 
operacional desse serviço e o valor do exemplar. Segundo o próprio jornal, o público leitor está concentrado nas classes C (46\%), D/E (22\%), B (26\%) e A $(6 \%)$ e exerce atividades como: técnico de secretariado, recepcionista, copeiro, cozinheiro, porteiro, auxiliar de enfermagem, operador de computador, técnico de mecânica, borracheiro, pintor de obras e auxiliar de importação. ${ }^{3}$

\section{A "SEXUALIDADE" NOS RELATOS DE LEITORES: VIDA A DOIS E VIDA ÍNTIMA}

Vida a Dois é uma seção da revista dominical Canal Extra que exibe relatos dos leitores, os quais se correspondem com a coluna através do envio de cartas pelo correio convencional. Estudos mostram que o envio de cartas de leitores para o jornal configura-se como um "dispositivo de sedução". Convidando as pessoas a escrever, os jornais, estrategicamente, lhe dão o sentimento de participar da narrativa jornalística (Martín-Barbero, 1997). Em Vida Íntima, coluna dominical de $O$ Globo, os leitores podem se comunicar com o especialista através do correio eletrônico (Internet).

A leitura dos relatos de leitores dos dois veículos indica que as notícias são construídas em torno dos mesmos temas: insatisfação no casamento, infidelidade, ausência de diálogo na relação conjugal, solidão, problemas com o sexo e/ou a sexualidade; porém as concepções e horizontes colocados pelos veículos em relação aos temas, bem como a forma de "encará-los/solucioná-los", são distintas.

Santos (1987) e Figueira (1987) discutiram como a mídia difundiu conceitos analíticos a um público leigo, popularizando a psicanálise e incorporando-a ao sistema moral, permitindo que o público pudesse identificar seu sofrimento e sua queixa como um problema psicológico. ${ }^{4} \mathrm{~A}$ análise contrastiva de $O$

3 "O VIDA GANHA publica toda semana uma tabela de salários preparada pelo Grupo de Permuta de Informações Salariais do Rio de Janeiro (GRUPISA). São apresentados o maior e o menor valor pagos no mercado para 50 cargos. A pesquisa é feita em 70 empresas no Rio de Janeiro, com informações de quase 400 profissões, que representam um universo de meio milhão de trabalhadores" (Extra, edição de 24/01/1999).

4 Ao examinar uma coluna em duas conjunturas, Santos verificou a articulação entre a modernização dos valores no plano das relações conjugais e a disseminação de um modo de pensar fundado na psicanálise, observando que a coluna escrita por uma consultora leiga e aquela redigida por uma psicanalista apresentavam discrepância quanto à forma de aconselhamento. Ou seja, a revista modificou seu código de
Globo e Extra revela que os relatos de Extra são fragmentados, redigidos em frases curtas e relativamente simples e apresentados em poucas linhas, quando comparados à forma como são exibidas as perguntas dos leitores de $O$ Globo. Os pequenos trechos disponibilizados pelo veículo sugerem leitores pouco escolarizados, menos acostumados a falar de si e expor suas intimidades. Em geral, os discursos apontam para uma busca de aprendizado/educação sexual. Estes leitores recebem, no texto jornalístico, um consentimento moral e legitimado: as cartas são respondidas por profissionais de saúde - sexólogos, psicólogos e psicanalistas, e em menor escala, psicoterapeutas e até professores de artes sensuais, todos representados como especialistas ou detentores de um saber legítimo sobre sexo. A coluna de $O$ Globo publica apenas uma carta, na íntegra ou quase. Os relatos revelam leitores escolarizados e bem articulados com a escrita, que expõem seus sentimentos, desejos e angústias de modo fluente. A maioria dos relatos incorpora a vivência e a experiência profissional, que se mostram como um bem para aquele público. A confissão de intimidades recebe os comentários de um renomado psicanalista em meia página de jornal.

$\mathrm{O}$ aconselhamento de Extra se apresenta como uma intervenção direta, por meio de julgamentos de valores e separação de comportamentos lícitos e ilícitos. A utilização de imperativos morais (por exemplo, "Procure um novo amor!") aponta para situações que direcionam o leitor para caminhos definitivos. Já na coluna Vida Íntima não se emitem julgamentos e se faculta ao leitor a possibilidade de optar a partir de uma prática que, ao invés de propor significados fechados a partir de idéias prontas, possibilita que ele construa por si próprio os caminhos decorrentes de seus entendimentos. Esta operação é

informação com a substituição de uma consultora por outra. A consultora leiga reverenciava valores como tradição, experiência e sabedoria que resultavam na proposição de soluções para o sofrimento das leitoras através de fórmulas "simpáticas". Já a coluna escrita por uma consultora psicanalista estava ancorada no conhecimento e experiência profissionais, respaldando uma visão de valores mais flexível quanto às tradições. $\mathrm{O}$ conselho dava lugar a um questionamento de conflitos, sem a intenção de provocar um sentimento de alívio. Segundo Santos, o objetivo era, então, apostar na reconstrução das idéias do leitor e no questionamento de atitudes atribuídas ao sexo, ampliando suas possibilidades de escolha, autonomia e independência, a medida que a busca de soluções pessoais, individuais e únicas para os problemas e o "protagonismo" são centrais no aconselhamento psicanalítico. 
feita através do uso de metáforas e histórias, nunca de conselhos acabados. A dimensão subjetiva do leitor é incentivada a manifestar-se.

A maioria dos relatos publicados, nos dois jornais, é de mulheres. No entanto, numa das poucas cartas redigidas por homem - "Preciso de dicas para namorar" - há interessantes pontos para discussão. Dizia o leitor: "Nunca namorei e me interesso muito em aprender. Tenho uma noção de como se beija, mas gostaria de ter algumas dicas para a primeira vez" (Vida a Dois, 30/08/1998). A carta foi respondida por uma psicanalista, que retrucou: "Não se aprende a namorar (...) as coisas acontecem naturalmente. (...) Libere suas emoções e deixe fluir os sentimentos". Ilustrava o cenário uma imagem de rosto masculino, fazendo "biquinho", e um ponto de interrogação diante dele. O exemplo exibe uma visão essencialista, que reforça a idéia de que as práticas ligadas ao amor e ao sexo "acontecem naturalmente", estando atreladas à ordem do destino e da predestinação. Os discursos dos profissionais de saúde coletados no jornal tendem a naturalizar a sexualidade e o desejo, fazendo uma conjunção entre eles. O jornal reforça a visão biologicista presente no imaginário, que gira em torno da sexualidade e do desejo, sem que a dimensão do aprendizado social seja lembrada.

Um dos temas recorrentes em Vida a Dois é a iniciação sexual. Como demonstra a literatura antropológica, ser "virgem" ainda denota um valor central na organização dos valores sobre sexualidade dos segmentos populares (Heilborn \& Gouveia, 1999). Sem dúvida, este é um valor produzido e reforçado pelo jornal Extra, no qual são comuns frases como "o homem tira a virgindade da mulher", "medo de perder a virgindade", "garota comportada é garota virgem", "meus pais acham que sou virgem" e "tenho medo de ficar com uma imagem negativa diante da família".

De fato, vários registros no banco de dados mencionam a virgindade como tema recorrente no discurso de Extra também em outros espaços do veículo. Em $O$ Globo as matérias apontam para uma diminuição da importância da virgindade como valor. Na realidade, poucas referências disponíveis no banco de dados revelam a presença deste assunto. Ele surge, sobretudo, em reportagens publicadas na Revista da $T V$ (fazendo referência a tramas novelísticas ocasiões em que podem aparecer sob o signo de "pureza" e "entrega"). Um relato publicado em Vida Íntima expõe uma mulher de 24 anos que diz, em 57 linhas, ser virgem e não conseguir relacionar-se com homens de sua idade. Relata, em detalhes, só desejar homens comprometidos e revela ser bonita e atraente. Diz ainda ter feito análise, afirma sua atuação profissional e expõe sua descrença no casamento e em filhos. Não faz pergunta alguma e não indica preocupação com a virgindade. $O$ relato foi respondido pelo psicanalista, que utilizou em seu aconselhamento várias metáforas e histórias, além de termos como "inconsciente", "racionalidade" e "triângulo edipiano". ("Quando o homem desejado já é comprometido", Vida Íntima, 27/09/1998).

Outro tema bastante presente nesses espaços de manifestação dos leitores, ainda que de forma bastante difusa, refere-se ao "prazer sexual". O universo de cartas de leitoras de Extra revela que algumas mulheres não obtêm prazer sexual (descrito pelo jornal como "gozar" ou "chegar ao orgasmo") e algumas têm práticas sexuais das quais não gostam, como o sexo anal, para satisfazer os seus parceiros. Os relatos apresentam a preocupação das leitoras com o prazer e a avaliação dos homens, bem como certa submissão à satisfação destes. A construção de orações que utilizam pronomes adversativos e o recurso à dramatização (que alude à idéia de impossibilidade) estão presentes para designar a insatisfação sexual das leitoras de Extra: ("Quando transamos, eu não gozo. E acabo fazendo sexo anal só porque ele pede. Por que isso acontece comigo?"; "Onde fica o tal ponto G? Quem deve saber onde ele fica? Eu ou meu namorado? Como posso encontrá-lo? "Não sei como é o orgasmo", "Gosto dele, mas sou frígida” (Vida a Dois, 24/05/1998).

O "orgasmo" aparece como uma experiência desconhecida ao universo do leitor: "Tive poucos namorados e com nenhum deles atingi o que dizem ser orgasmo. Às vezes sinto um arrepio intenso. Será que é orgasmo?”. O jornal se propõe a elucidar tal experiência através de aconselhamento proferido por sexologistas num exercício de pedagogia sexual: "O orgasmo não é uma cobrança e sim o clímax. Se você se realiza e tem prazer no jogo amoroso, esse é o início do seu orgasmo" (Vida a Dois, 20/09/1998).

Ao lado da insatisfação sexual, estão presentes "queixas" relativas às relações conjugais, depreendendo-se um código de rígida assimetria de gênero, que se manifesta em tempos e formas diferenciais de homens e mulheres para a obtenção de prazer, como pode ser visto no quadro a seguir: 


\begin{tabular}{|c|c|c|}
\hline $\begin{array}{l}\text { Meu marido não é } \\
\text { carinhoso }\end{array}$ & $\begin{array}{l}\text { Gosto dele, mas sou } \\
\text { frígida }\end{array}$ & $\begin{array}{l}\text { Meu marido quer } \\
\text { transar todo dia }\end{array}$ \\
\hline $\begin{array}{l}\text { "Tudo é muito rápido } \\
\text { quando eu e meu } \\
\text { marido estamos na } \\
\text { cama. Ele me deseja, } \\
\text { mas não consegue } \\
\text { acompanhar meu } \\
\text { ritmo. Gostaria que ele } \\
\text { me fizesse mais } \\
\text { carícias". } \\
\text { A leitora assina como } \\
\text { "A insatisfeita" (Vida a } \\
\text { Dois, 07/02/1999). }\end{array}$ & $\begin{array}{l}\text { "Gosto do meu } \\
\text { parceiro, mas estou } \\
\text { cansada de fingir sentir } \\
\text { orgasmo" (Vida a } \\
\text { Dois, 10/05/1998). }\end{array}$ & $\begin{array}{l}\text { “Meu marido quer } \\
\text { ter relações comigo } \\
\text { todos os dias, mas } \\
\text { me satisfaço com, no } \\
\text { máximo, duas vezes } \\
\text { por semana. Por que } \\
\text { sou assim?” (Vida a } \\
\text { dois, s/d). }\end{array}$ \\
\hline
\end{tabular}

O quadro acima chama a atenção para a escolha de alguns termos em detrimento de outros. A palavra "relações", utilizada amplamente para referência ao engajamento sexual, é comumente substituída pelo verbo "transar", linguajar mais coloquial e pouco utilizado no Jornal $O$ Globo. Também é interessante perceber no relato da leitora, de 22 anos, uma atribuição de normalidade ao desejo sexual do marido e de desvio ao seu próprio - porque "se satisfaz com duas vezes por semana". Afirma a leitora: "Quando estou com meu namorado, não consigo sentir orgasmo. O que está acontecendo comigo? Preciso de ajuda!" (Vida a Dois, 17/05/1998). O aconselhamento do sexologista inicialmente articula uma variação de desejo sexual de pessoa a pessoa dizendo que isso não é anormal, mas termina com uma frase no mínimo inusitada: "O certo é que muitas mulheres gostariam de estar no seu lugar" (Vida a Dois, 08/11/1998). Extra destaca frases de efeito que provocam uma noção de fatalidade ("por que sou assim?", "preciso de ajuda"), recurso pouco utilizado por $O$ Globo. "Quando o desejo sexual naufraga em melancolia" foi uma sugestiva e literária chamada de Vida Íntima para uma carta de leitor, publicada em 59 linhas. Um homem relatou estar casado desde muitos anos, ter tido uma vida profissional com bom êxito e, num determinado momento, ter ficado sem emprego, passando a ter a casa sustentada pelo salário de sua mulher. À época em que parou de trabalhar diz ter tornado menos frequientes suas relações sexuais, ter procurado um médico e constatado que não tinha problemas físicos. A análise metaforizada da carta cumpriu a função de fazer o leitor se autoquestionar, através do recurso ao aconselhamento indireto. $\mathrm{O}$ psicanalista empreendeu uma narrativa que tinha uma "moral da história" na qual se observa-se o curioso apagamento da impotência sexual relatada pelo leitor. $\mathrm{O}$ tratamento dado à matéria foi sutil, assim como a singela ilustração que a acompanhava.

Em relação à temática do "prazer sexual", o leque de questões de $O$ Globo se apresenta como mais ampliado em relação ao outro veículo, abrangendo significados como "prazer", "orgasmo", "sexo seguro", "ejaculação", "satisfação sexual", "impotência", etc. Descreve uma maior exposição às sensações, uma preocupação com o sentimento de prazer e uma percepção aguçada de si. Os comentários proferidos pelos especialistas - de abordagem psicanalítica na maioria das vezes - não estão balizados pelos conceitos de "certo" e "errado", e se apresentam de modo mais flexível quanto às possibilidades de experiências sexuais dos leitores. Os eventos recorrem a metáforas e contos para comentar determinadas situações. Supõe-se que o veículo idealize um leitor escolarizado, minimamente adestrado a um hábito regular de leitura e pelo menos iniciado em assuntos que dêem margem para serem discutidos à luz da psicanálise.

\section{TESTES PARA MEDIR CONHECIMENTOS AMOROSOS E SEXUAIS}

Extra propõe aos leitores, em sua revista dominical, uma forma de intervenção para medir seus conhecimentos em torno de temas relativos à sexualidade. A coluna Teste se dirige aos leitores através do recurso de interrogação, interação que (se imagina) é estabelecida quando o leitor adere à leitura e responde às perguntas propostas pelo jornal. São apresentadas ao leitor as definições do significado daquilo que se propõe inquirir. Ao final do teste, o leitor deve conferir o total de pontos das respostas que assinalou numa tabela. Um rápido diagnóstico é apresentado e, com ele, um conselho, de modo imperativo, com base no provável "desvio" mapeado a partir do perfil. $\mathrm{O}$ ato de amar, por exemplo, está restrito a um campo de possibilidades através de algumas proposições:

\section{Você sabe amar?}

\begin{tabular}{|c|c|}
\hline $\begin{array}{ll}\text { Com quem você No namoro é errado: } \\
\text { viveria um } \\
\text { belo a) arriscar a vida por } \\
\text { romance? } & \text { ele } \\
\begin{array}{ll}\text { a) um conquistador } & \text { b) viver em função do } \\
\text { b) um sádico } & \text { outro } \\
\text { c) um aventureiro } & \text { c) esquecer de ligar } \\
& \text { para os amigos }\end{array}\end{array}$ & $\begin{array}{l}\text { dele franqueza de } \\
\text { b) espírito, ser espontâneo } \\
\text { c) sinal de pureza, até } \\
\text { dispensa o sexo }\end{array}$ \\
\hline 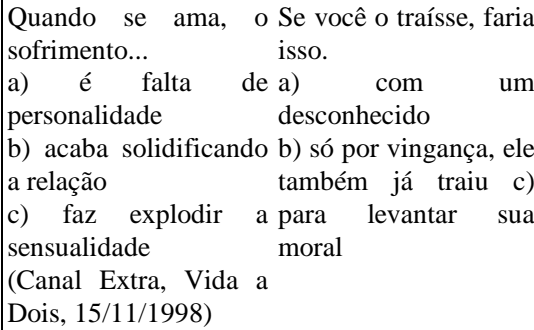 & $\begin{array}{l}\text { a a ama com } \\
\text { ade } \\
\text { a fim de um } \\
\text { ado }\end{array}$ \\
\hline
\end{tabular}


Caso a pessoa não apresente nenhum "desvio" a partir do total de pontos resultante de suas respostas, ela é parabenizada: "de 9 a 12 pontos: você é mestre na arte de amor. Para você o amor é realmente lindo". No entanto, se o respondente fez "acima de 13 pontos: é melhor você confiar mais no seu parceiro". Para aqueles que marcaram "até 8 pontos: Você acha que é auto-suficiente. Aprenda a dividir".

Os dois testes apresentados a seguir abordam a socialização sexual, um deles focalizando meninos e o outro, meninas $\mathrm{O}$ primeiro inquiria o melhor momento de educar sexualmente um adolescente e apresentava como opções de respostas: "quando ele começa a questionar"; "nunca, é melhor deixá-lo descobrir sozinho"; "quando a TV exibe cenas pesadas". Perguntava ainda: "O que fazer com seu filho mais novo que vive se masturbando?", apresentando como proposições "levá-lo ao médico"; "deixá-lo de castigo"; "conversar com ele". As referidas perguntas sugerem um imaginário de preocupação paterna em relação à sexualidade dos jovens. Não propõem, por exemplo, um diálogo franco entre pais e filhos ou mencionam as influências do processo de socialização escolar; e, em todas as opções ofertadas, o ato da masturbação merece punição, destacando-se como prática sexual desaconselhável: o filho é punido diretamente, através de castigo, ou tido como doente - pois precisa ser levado ao médico, e, na melhor das hipóteses, terá de conversar com sua mãe ou pai. Não há um item que privilegie a individualidade e a vontade da pessoa e a possibilidade da masturbação - exemplificando como a sexualidade é controlada pelo crivo da família e da medicina. A matéria que versava sobre educação sexual das meninas inquiria sobre o "uso da camisinha nos relacionamentos sexuais", "os métodos anticoncepcionais e as DSTs", "a gravidez", "a prevenção à aids" e "a iniciação sexual". O relacionamento sexual foi descrito como "a hora H" e a iniciação sexual como "a hora certa". Esta última apresentava como possibilidades um "namoro sério", um "casamento" ou um "encontro com alguém especial", correlacionando a experiência sexual feminina a um relacionamento afetivo. A experiência sexual está circunscrita dentro de um quadro de relacionamento estável, portanto está absolutamente relacionada ao vínculo amoroso. Neste exemplo, não há menção ao tema da masturbação. Nota-se, no entanto, que a matéria, endereçada às mães, propõe certa medicalização ao mencionar educação sexual, métodos anticoncepcionais, DST/AIDS e gravidez.

\section{Educação sexual}

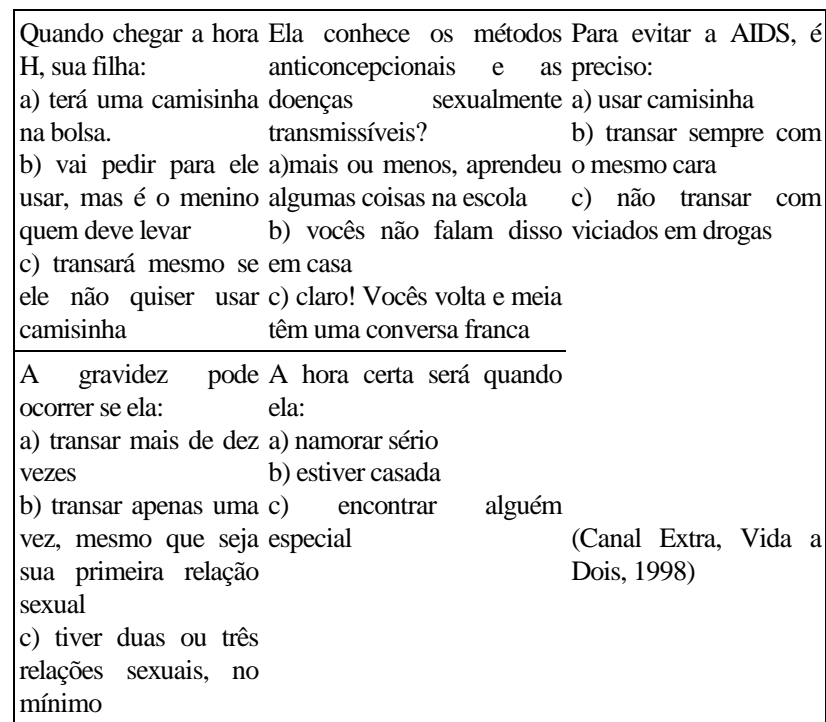

O casamento é outro tema de interesse da coluna e articulado à sexualidade. Para saber se "o seu casamento está em alta", a leitora (mulher) é levada a refletir sobre questões presentes no imaginário moderno: a idéia de que esse vínculo não se sustenta sem o exercício sexual (Bozon, 2004), a reflexão sobre o exercício profissional e a divisão sexual do trabalho. Vocêfaz sexo menos de duas vezes por mês? A iniciativa sexual sempre é sua?Vocês têm brigado mais nos últimos meses?Faz mais de uma semana que vocês não conversam sobre sexo?Você trabalha fora $e$ cuida da casa sozinha? Você está numa fase de construção da sua vida profissional que exige todas as suas forças? Você tem olhado muito para outros homens ultimamente?O seu trabalho caiu na rotina, não tem mais graça?

Não obstante, há vários exemplos de matérias que chamam a atenção para o infortúnio de não se ter um matrimônio. Numa delas, "A quantas anda sua energia sexual?" (Vida a Dois, 21/06/1998), a infelicidade de uma solteira inserida em um círculo de amigos casados era problematizada. O sexo incentivado é aquele que acontece no âmbito de casamentos heterossexuais, colocando em foco valores ideais de masculinidade e feminilidade. No entanto, a participação dos personagens neste vínculo os torna vulneráveis à infidelidade, que pode manchar a honra daqueles que são traídos. Inscrita num espaço de evitação, a traição gera títulos como "o que mata é a incerteza" (Sessão Extra, Tom Cavalcante, 06/09/1998), "um forte candidato a peixe chifrudo" (Extra, João Máximo, 06/09/1998) e "se arrependimento matasse" (Canal Extra, 20/09/1998), entre outros.

A diferença de gêneros está bastante acentuada em vários testes que se propõem a abordar as práticas sexuais. Esta abordagem diferencial também dialoga 
com o apagamento simbólico da sexualidade no processo de envelhecimento:

\section{Você entende de sexo?}

\begin{tabular}{|c|c|}
\hline $\begin{array}{l}\text { Com o passar dos anos, o homem: } \\
\text { a) fica impotente } \\
\text { b) perde totalmente o interesse pelo } \\
\text { sexo } \\
\text { c) fica mais tarado }\end{array}$ & $\begin{array}{l}\text { Se a mulher gosta muito de sexo, } \\
\text { ela é: } \\
\text { a) sem vergonha } \\
\text { b) o sonho de todo homem viril } \\
\text { c) fogosa }\end{array}$ \\
\hline $\begin{array}{l}\text { Na sociedade moderna, a frigidez } \\
\text { feminina é: } \\
\text { a) cada vez mais constante } \\
\text { b) lenda } \\
\text { c) cada vez mais rara }\end{array}$ & $\begin{array}{l}\text { O sexo anal: } \\
\text { a) sem camisinha é perigoso } \\
\text { porque pode transmitir AIDS } \\
\text { b) não é natural } \\
\text { c) é muito legal e mais prazeroso }\end{array}$ \\
\hline $\begin{array}{l}\text { (Canal Extra, Teste, 24/05/1998. Dua } \\
\text { sexual apresentadas no início do } \\
\text { matéria). }\end{array}$ & as das questões acerca da educação \\
\hline
\end{tabular}

Há uma sutil menção à existência de um binômio mulher frígida $X$ mulher que gosta muito de sexo. A representação projetada sobre esta última é elaborada de modo que as proposições possíveis formuladas pelo discurso jornalístico não contemplem os direitos e a individualidade de apreciar o sexo. "Gostar muito de sexo" torna a mulher "sem vergonha", "fogosa" ou simplesmente "complementar" ao homem viril. O arcabouço do discurso é montado de forma que se denigre a imagem da mulher ou se faz com que ela esteja servindo ao ideal de masculinidade perpetuado pelo jornal. Não há margem, enfim, para a construção da individualidade que tenha como valor estruturante a sexualidade. O discurso é perpassado por uma lógica de moralidade. "Entender de sexo" significa marcar a resposta mais aceitável, do ponto de vista do veículo, para questões pontuais acerca da educação sexual, masturbação, frigidez feminina, prática sexual feminina e sexo anal; ainda que se ventilem algumas aberturas ao ponto de vista moral, como a sugestão ao prazer anal. $\mathrm{O}$ exemplo abaixo dirige-se ao universo masculino:

\section{Você só pensa em sexo?}

\begin{tabular}{|c|c|c|}
\hline $\begin{array}{l}\text { Você reclama quando } \\
\text { ela te acaricia de um } \\
\text { jeito que não gosta? } \\
\text { a) não, mas às vezes } \\
\text { sinto vergonha } \\
\text { b) às vezes } \\
\text { c) sempre }\end{array}$ & $\begin{array}{l}\text { Qual a época que te dá } \\
\text { mais tesão? } \\
\text { a) no verão } \\
\text { b) nunca pensei nisso } \\
\text { c) o ano inteiro }\end{array}$ & $\begin{array}{l}\text { Na hora das } \\
\text { carícias, é você } \\
\text { quem toma a } \\
\text { iniciativa? } \\
\text { a) sim } \\
\text { b) às vezes } \\
\text { c) não }\end{array}$ \\
\hline $\begin{array}{l}\text { Você está satisfeito } \\
\text { com ela ou tem } \\
\text { vontade de sair com } \\
\text { outras? } \\
\text { a) é ela quem eu amo } \\
\text { b) imagino como } \\
\text { seria com outras } \\
\text { mulheres } \\
\text { c) acho que estou feliz } \\
\text { com ela }\end{array}$ & $\begin{array}{l}\text { O que mais importa na } \\
\text { transa? } \\
\text { a) frases sensuais } \\
\text { b) liberar geral } \\
\text { c) esquecer da vida } \\
\text { O que mais o atraiu } \\
\text { nela? } \\
\text { a) o corpo } \\
\text { b) a sinceridade } \\
\text { c) a malícia }\end{array}$ & $\begin{array}{l}\text { Sexo é indispensável? } \\
\text { a) claro! } \\
\text { b) nem sempre } \\
\text { c) a amizade deve prevalecer } \\
\text { antes de tudo, em qualquer } \\
\text { relação }\end{array}$ \\
\hline
\end{tabular}

Assinalando hipoteticamente "reclamar sempre de uma carícia mal-feita", "imaginar como seria sair com outras mulheres", "tomar a iniciativa na hora das carícias", "sentir-se atraído pela malícia da companheira", "sentir tesão todo o ano", "esquecer da vida na hora da transa" e concluir que "sexo é indispensável” levam a um diagnóstico preciso: "Você não é fácil... Só pensa "naquilo". Se está dando certo, aproveite". Em contrapartida, "sentir vergonha de reclamar quando acariciado de um jeito que não agradou", "considerar-se feliz com a sua própria mulher", "não tomar a iniciativa na hora das carícias", "sentir-se atraído pela sinceridade da companheira", "nunca ter refletido sobre a época do ano em que sente mais tesão", "considerar que frases sensuais são o que mais importam na hora da transa" e "considerar que a amizade deve prevalecer antes de qualquer coisa na relação" levam a uma avaliação um tanto desesperadora: "Sua namorada deve ter motivos para reclamar. Dê mais atenção à moça!".

A satisfação sexual foi tema de teste similar no qual se inquiria à leitora sobre a "posição sexual mais prazerosa", o "clímax (quem "chegava" primeiro e o "melhor jeito" para atingi-lo - masturbação, sexo oral ou fantasias)", "o que tornava o sexo interessante (as roupas, a cama ou a companhia)" e "o que era mais erótico" ("ouvir que é interessante", "dormir sem roupas" ou "despir-se frente a um espelho"). Os rápidos diagnósticos traçados pelo jornal indicavam: "Você vive o sexo com prazer e intensidade"; "o sexo ainda não é o ideal, mas dá pro gasto" (grifos nossos); "Você se satisfaz com pouco" (Canal Extra, 07/06/1998).

Há, pois, uma enorme diferença quando o discurso é dirigido ao homem ou à mulher. Notam-se definições sutis acerca de valores sexuais "incentivados" no aconselhamento dado ao homem. Há certa permissividade em relação a uma poligamia masculina (ter vontade de sair com outras mulheres valoriza o ideal de homem proposto pelo jornal), uma valorização da iniciativa masculina nas carícias sexuais, bem como uma valorização dos atributos físicos em detrimento dos sentimentos. Entender de sexo, para o jornal, está circunscrito a "fazer carícias", "sentir atração", "tesão" e ao ato sexual em si ("transar"). Por outro lado, as representações acerca da masculinidade apresentadas no jogo jornalístico são colocadas em discurso numa matéria dirigida às mulheres, que lhes inquiria: "Que tipo de mulher tem mais chance de se arranjar? A que é gostosa e liberada, a inteligente ou a bonita e bem comportada?". O teste perguntava, ainda, em relação ao sexo, "se homens sabem mais do que mulheres; não 
admitem que têm dúvidas; ou sabem menos do que as mulheres". Observando os valores atribuídos pelo jornal às questões, a resposta mais valiosa, em relação à primeira proposição, seria "a mulher inteligente", e, no caso da segunda pergunta, a resposta "certa" seria "homens não admitem que têm dúvidas sobre sexo". A interrogação desenfatiza o sexo como um valor positivo. As matérias coletadas referem-se a ideais de homens e mulheres atrelados a uma lógica hierárquica de gênero, na qual os modelos culturalmente valorizados do masculino estão associados ao homem heterossexual e viril, estando a mulher associada à vergonha (ou a sua falta). De forma similar, outro teste inquiria: "Homem galinha, mas que troca mulher por futebol... a) não gosta tanto assim de mulher; b) sabe dividir as duas paixões; c) precisa esquecer a bola e dar mais atenção à gata". Segundo a escala do jornal, quem marcou a maioria das respostas "a" "conhece como ninguém o universo masculino", e quem teve a maioria das respostas em "c" deve fazer "um curso intensivo sobre homens!”.

\section{CONSIDERAÇÕES FINAIS}

\begin{abstract}
"damos muita ênfase na questão da saúde, do Viva Mais, do sexo dando informações, o máximo de informações possíveis... uso de camisinha, tudo, sem... preconceitos...(...). Antigamente, o jornal popular se baseava numa fórmula simples: SS (sexo e sangue).Você botava uma manchete de polícia 'passou o facão na mulher, fez ela sangrar até a morte', botava sangue na manchete e dava uma foto desse tamanho de uma mulher com os peitões de fora, estaria resolvido o jornal popular. Mudou o conceito, isso é uma fórmula vulgar e barata. O sexo não é apresentado de uma forma vulgar. Se você olha o Extra não tem um pôster de mulher pelada." (Editor-executivo de Extra).
\end{abstract}

O panorama geral da sexualidade nos jornais revela grande incidência de espaços caracterizados por notícias que abordam aspectos relacionados à vida privada. $\mathrm{O}$ artigo visou compreender o que se constituía como sexualidade para os dois veículos. A análise contrastou jornais destinados a segmentos sociais diferenciados.

A epígrafe acima é parte de um trecho da entrevista realizada com o editor executivo do "jornal popular". Para corroborar sua fala, o editor apanha um jornal sobre sua mesa e expressa: "A nossa capa do Sessão Extra é ... - sem graça, sorri pela coincidência de assunto - ... Oba, hoje tem Luana" (...) a Luana, que é a grande símbolo sexual, vai ficar... vai ficar pelada..." (Tratava-se de uma matéria que abordava o desnudamento de uma personagem em uma minissérie televisiva).

Como observado nos exemplos, as respostas dos testes são induzidas pela forma como são colocadas as questões, ou, ainda, os relatos dos leitores são editados a partir da mensagem que o jornal deseja passar. Como discutiu Bourdieu (1983) analisando pesquisas de opinião, a verdadeira opinião pública inexiste, na medida em que é decorrente dos vieses contidos na formulação das proposições feitas às pessoas.

Becker (1997) discute que uma variedade de campos (incluindo o jornalístico) pensam saber algo sobre a sociedade (neste caso, de representá-la), na maioria das vezes não reconhecendo (e até desconhecendo) que qualquer representação da realidade social é parcial. Neste artigo buscou-se problematizar a forma como a mídia descreve (ou imagina?) a representação dos leitores sobre alguns aspectos da sexualidade.

Chama-se a atenção para a existência de um "ideal modernizador" - para usar a expressão cunhada por Figueira (1987) - o que pode ser percebido através das reportagens que utilizam novelas para discutir temas sobre sexualidade, envolvendo personagens que funcionam como possibilidade de identificação para todos. Em alguns momentos, a uma construção de visão de mundo tradicional soma-se um ideal de medicalização, como pôde ser observado em várias matérias preocupadas com o sexo seguro, por exemplo. $O$ Globo não se caracteriza como um jornal absolutamente moderno, mas boa parte de suas matérias alude a atitudes e ideais modernos, dirigindose a um público supostamente individualizado, escolarizado e, em muitas vezes, adepto da racionalidade psicológica. O discurso de $O$ Globo revela vários e difusos discursos sobre sexualidade: desde algumas construções mais tradicionais a outras mais frouxas quanto a restrições de normas referentes às concepções mais conservadoras presentes no Extra. E - diga-se - a modernidade observada nas páginas de $O$ Globo (e reiterada, sobretudo, pelos cadernos de informática e viagem) não exclui formas tradicionais de estilos de vida. Em se tratando da interação dos meios de comunicação com os leitores, novos valores se sobrepõem aos antigos sem alterá-los substancialmente (Velho, 1994). A incorporação e retroalimentação de valores conformam as representações sociais, reiterando a mídia como uma forte agência socializadora que trabalha normatividades e discursos diferentes para segmentos 
sociais distintos no que concerne à difusão da idéia de sexualidade como um dos temas de maior interesse na contemporaneidade (Foucault, 1993, 1999).

\section{Agradecimentos}

Agradecimentos são dirigidos à professora Maria Luiza Heilborn, que me orientou à época da realização do estudo original, à professora Vera Paiva pelos valiosos comentários e edição deste texto, e a Felipe Rios e Juan Carlos Raxach pelo constante diálogo.

\section{REFERÊNCIAS}

Becker, H. (1997). Métodos de Pesquisa em Ciências Sociais. São Paulo: Hucitec.

Bourdieu, P. (1983). A opinião pública não existe. Em Questões de sociologia (pp. 173-182). Rio de Janeiro: Marco Zero.

Bourdieu, P. (1996). A influência do jornalismo. Em Sobre a Televisão (pp. 99-120). Rio de Janeiro: Jorge Zahar.

Bozon, M. (2004). Sociologia da sexualidade. Rio de Janeiro: Fundação Getúlio Vargas.

Brigeiro, M., \& Maksud, I. (no prelo). A aparição do Viagra na cena pública brasileira: corpo, gênero e sexualidade na mídia. Revista Estudos Feministas.

Burke, P. S. N. (1996). O jornal em pauta: um estudo sobre a coluna de cartas dos leitores do JB. Rio de Janeiro: Museu Nacional.

DaMatta, R. (1993). A obra literária como etnografia. Em Conta de Mentiroso. Sete ensaios de antropologia brasileira (pp. 35-58). Rio de Janeiro: Rocco.

Figueira, S. (1987). Uma nova família? O moderno e o arcaico na família de classe média brasileira. Rio de Janeiro: Jorge Zahar.

Foucault, M. (1993). História da Sexualidade 1: a vontade de saber. Rio de Janeiro: Graal.

Foucault, M. (1999). A ordem do discurso. São Paulo: Edições Loyola.

Galvão, J. (1992). AIDS e imprensa: um estudo de antropologia social. Dissertação de Mestrado, Programa de pós-graduação em Antropologia Social, Museu Nacional, UFRJ, Rio de Janeiro.

Heilborn, M. L., \& Gouveia, P. (1999). "Marido é tudo igual": mulheres populares e sexualidade no contexto da AIDS. Em R. Parker \& R. M. Barbosa (Orgs.), Sexualidades pelo avesso: direitos, identidades e poder (pp. 83-99). Rio de Janeiro: IMS/UERJ; São Paulo: Editora 34.

Herzlich, C., \& Pierret, J. (2005). Uma doença no espaço público. A AIDS em seis jornais franceses. PHYSIS: Revista de Saúde Coletiva, Rio de Janeiro, 15(Suplemento), 71-101.

Lattman-Weltman, F. (1992). Jornalistas: agenciando a cidadania, publicizando o privado. Dissertação de Mestrado, Programa de pós-graduação em Sociologia e Antropologia, Universidade Federal do Rio de Janeiro, Rio de Janeiro.

Luz, M. (1979). As instituições médicas nos jornais. Em As instituições médicas no Brasil (pp. 205-242). Rio de Janeiro: Graal.

Maksud, I. (2000). Sexualidade e mídia: uma análise antropológica do discurso jornalístico. Dissertação de Mestrado não publicada, Programa de Pós Graduação em Saúde Coletiva do Instituto de Medicina Social, Universidade Estadual do Rio de Janeiro, Rio de Janeiro.

Moraes, N. A (1998). Saúde, Imprensa e Governo. Tese de Doutorado. São Paulo, PUC.

Martín-Barbero, J. (1997). Dos meios às mediações. Comunicação, cultura e hegemonia. Rio de Janeiro: Editora UFRJ.

Santos, T. C. (1987). De Dona Letícia a Carmen Silva: as revistas femininas e a modificação de comportamento da mulher. Em S. Figueira (Org.), Uma nova família? O moderno e o arcaico na família de classe média brasileira (pp. 83-98). Rio de Janeiro: Jorge Zahar.

Spink, M. J., Medrado, B., Menegon, Vera. M., Lyra, J., \& Lima, H. (1997). A construção da AIDS-notícia. (Relatório Projeto Imprensa CN DST e Aids/MS). São Paulo: Ministério da Saúde.

Velho, G. (1994). Cultura popular e sociedade de massas. Em Projeto e Metamorfose. Antropologia das sociedades complexas (pp. 63-70). Rio de Janeiro: Jorge Zahar.

Recebido em 09/06/2008 Aceito em 01/09/2008
Endereço para correspondência :

Ivia Maksud. ABIA, Av. Presidente Vargas, 446, 13º andar, Centro, CEP 20071-907, Rio de Janeiro-RJ.E-mail: maksud@abiaids.org.br 